Article

\title{
Relationship between Negative Work Situation, Work-Family Conflict, Sleep-Related Problems, and Job Dissatisfaction in the Truck Drivers
}

\author{
Dong Seok Shin ${ }^{1} \mathbb{D}$ and Byung Yong Jeong $2, * \mathbb{D}$ \\ 1 Korea National Industrial Convergence Center, Korea Institute of Industrial Technology, Ansan 15588, Korea; \\ dsshin@kitech.re.kr \\ 2 Department of Industrial \& Management Engineering, Hansung University, Seoul 02876, Korea \\ * Correspondence: byjeong@hansung.ac.kr
}

Received: 11 September 2020; Accepted: 29 September 2020; Published: 1 October 2020

\begin{abstract}
Understanding the relationship between psychological factors of truck drivers is very important for accident prevention plans. This study investigates whether the negative work situation or work-family conflict positively affects sleep-related problems and whether sleep-related problems positively affect job dissatisfaction. The relationship was verified by structural equation modeling. The analysis was conducted with 184 truck drivers who drive daily from the 5th Korea Working Conditions Survey (KWCS) data. The structural equation modeling results found that work-family conflict (standardized path coefficient $=0.274$ ) and negative work situation (standardized path coefficient $=0.203$ ) had significantly affected sleep-related problems. Also, the sleep-related problems were more affected by the work-family conflict level than the negative work situation level. Sleep-related problems were found to correlate with job dissatisfaction (standardized path coefficient $=0.336$ ). The relationship between negative work situation and work-family conflict on sleep-related problems and job dissatisfaction will help establish preventive policies for truck drivers' safety and health.
\end{abstract}

Keywords: structural equation modeling; work-life balance; safety and health; job satisfaction

\section{Introduction}

\subsection{Truck Drivers and Purpose of Study}

Truck drivers who transport cargo to a local region or long-haul area play a role in the e-commerce and logistics industries [1]. In Korea Standard Classification of Occupations [2], truck and special truck drivers are classified into freight-vehicle drivers and special-purpose-vehicle drivers. Freight-vehicle is defined as a truck whose loaded weight is larger than the total weight of passengers inside, and a special-purpose-vehicle is a vehicle that is adequately designed to perform particular tasks [3]. In this study, truck drivers include freight-vehicle drivers and special-purpose-vehicle drivers. In 2018, there were 1,235,045 workers at 383,737 establishments in the freight trucking industry of South Korea [4].

Truck drivers' tasks include checking the transport records and delivering the vehicle to its destinations [1]. Truck drivers are treated as self-employed in South Korea [1]. Some self-employed truck drivers buy or lease trucks and go into business for themselves [1]. Truck drivers who are self-employed can control the number of workdays and their schedules. Truck drivers can maintain their income by long working hours because of intensified competition [5]. Self-employed truck drivers who purchase cars as installments are subject to economic pressure due to car payments and tend to increase workdays to increase their monthly income. They often have to drive until the late hours of the night, and they may experience irregular and insufficient meals [5]. 
Furthermore, large truck drivers may be away home for days or weeks, leading to insufficient sleep [6]. Lee and Jeong [1] pointed out that it is necessary to support truck drivers' chronic fatigue to prevent crashes caused by drowsy driving. Thus, truck driver is recognized as an occupation with the highest rates of injuries and illnesses [6,7].

Truck drivers may experience prolonged sitting and be exposed to many unhealthy conditions such as long driving distances, irregular shifts, insufficient rest, fatigue, and environmental hazards $[6,8]$. The drivers also have a stressful nature of work-tight timelines, congested roads, customers' rude behavior, the direct relationship of hours of work and incentives, and not enough time for relaxation [1,9].

Human-related factors caused $73.8 \%$ of the crashes in an analysis of tank truck crashes [10]. Human-related factors can be categorized into driver's properties [11], organizational factors [12], and direct causes of the crash (such as drowsy driving, inattention, and violation) [13]. These human-related factors are primarily associated with psychophysiological stressors, and psychophysiological stressors increase the likelihood of aggressive driving and poor mental health outcomes [14]. Thus, understanding the relationship between psychological factors is very important for accident prevention plans.

Psychological factors related to truck drivers include work situation, work-family conflict (or work-family balance), sleep-related problems, and job satisfaction [7-9,13-21]. Previous studies suggested that truck drivers' psychological factors were related to incidents [17-21]. However, there are a lack of studies analyzing the structural relationship between work situations, work-life balance, sleep-related problems, and job satisfaction.

This study aims to understand the factors influencing sleep-related problems and job dissatisfaction among truck drivers. A structural equation model combining the previous studies was performed to test three hypotheses on the relationships between negative working situations, work-family conflicts, sleep-related problems, and job dissatisfaction.

\subsection{Theoretical Background and Hypotheses}

\subsubsection{Sleep-Related Problems}

Driver drowsiness is common among truck drivers working extended hours $[6,9,13]$. Truck drivers suffer from sleep-related problems more than the general population [22]. Long working hours and unpredictable schedules are related to sleep problems [23,24]. Sleep-related problems increase risks for incidents and injuries [1,18-20,25]. Drowsiness was involved in $10.5 \%$ of the delivery truck crashes in South Korea [5]. These risks affect the profitability of the transportation company, medical costs for health insurance, and ultimately public safety [21].

\subsubsection{Work Situation}

The work situation is the social relationships that workers enter into their workplace [26]. It is related to the work environment, employment conditions, and employee's satisfaction [27]. It also includes individual rights and professional development opportunities within the company [28]. The truck driver's working conditions still are not good, and negative work situations are common $[1,5]$. In this study, negative work situations mean unfortunate or hostile social relationships that workers experience in their workplace. The negative work situation in the workplace saps energy and diverts attention from productivity and performance [20]. It can also lead to poor mental health outcomes, especially sleep-related problems.

This research created the following hypotheses:

Hypothesis 1 (H1): Negative work situations positively affect sleep-related problems.

\subsubsection{Work-Family Conflict}

Extended driving hours and irregular schedules can reduce the likelihood of family spending and lead to work-family conflict. Work-family conflict is the degree to which workers are not satisfied with 
the role of work and family: time-sharing, involvement, and satisfaction with work and family [16,17]. One primary reason for the work-family conflict is the lack of time-sharing due to extended driving hours [17]. Work-life conflict, social isolation, or unfortunate work situations can intrude into workers' private lives, leading to sleep-related problems $[17,18]$.

As explained in the literature above, this study hypothesized:

Hypothesis 2 (H2): Work-family conflicts positively affect sleep-related problems.

\subsubsection{Job Satisfaction}

Job satisfaction can be defined as the subjective interpretation of individual opinion based on the extent of fulfilling their requirements at work and in work situations, relationships, or activities related to it $[26,27]$. It also refers to a personal attitude, such as the overall impression, feeling, and evaluation that an individual has about the job. In this study, job dissatisfaction means the negative attitude or evaluation that workers have about the job. Job dissatisfaction can lead to negative outcomes [29]. Truck drivers suffer from sleep-related problems, and job dissatisfaction is common [13,19,21,25]. Sleep-related problems can cause a truck driver's job dissatisfaction. Thus, this research created the following hypotheses:

Hypothesis 3 (H3): Sleep-related problems positively affect job dissatisfaction.

\section{Materials and Methods}

\subsection{Data Collection}

This study used data and questionnaires from the 5th Korea Working Conditions Survey (KWCS) in 2017. KWCS is a national survey to investigate workers' working conditions and risk factors by industry [30]. The questionnaire used in this study is identical to that of the 6th European Working Conditions Survey (EWCS) [31]. The raw data of the KWCS was received from the Institute for Occupational Safety and Health [30].

In the 5th KWCS, 50,205 workers participated in proportion to each region's population in South Korea. Among them, drivers in the freight trucking industry were selected as this study's subjects. A total of 184 professional truck drivers were extracted as the final data. All of them were male, with $11.4 \%$ of those $\geq 60$ years, and $38.6 \%$ of those in their 50 s. The mean of driver's age was 54.9 years, with a standard deviation of 9.40 .

\subsection{Research Variables}

The research variables consisted of latent variables for a negative work situation, work-family conflict, sleep-related problems, and job dissatisfaction. Table 1 shows the latent variables and measurement variables for each latent variable. As shown in Table 1, all measurement variables were scored to the Likert scaling from 1 to 5 .

Negative work situation was based on the Q49 questions of the 2017 KWCS questionnaire (same as Q61 questions of the 2015 EWCS questionnaire) [31]. Some of the Q49 measurement variables in the KWCS questionnaire were removed through prior reliability analysis. The measurement variables for the negative work situations in Table 1 represent the results after prior removal.

Work-family conflict was represented by the Q38 questions of the 2017 KWCS questionnaire (same as Q45 questions of the 2015 EWCS questionnaire). As shown in Table 1, these questions have five measurement variables on work-family conflict [31].

Sleep-related problems were represented by the Q63 questions of the 2017 KWCS questionnaire (same as Q79 questions of the 2015 EWCS questionnaire). As shown in Table 1, these questions have three measurement variables on sleep-related problems [18]. 
Job dissatisfaction was based on the Q71 questions of the 2017 KWCS questionnaire (same as Q90 questions of the 2015 EWCS questionnaire). As shown in Table 1, it is the same as Warr et al.'s job dissatisfaction index [32].

Table 1. Research variables of this study.

\begin{tabular}{|c|c|c|c|}
\hline Latent Variable & Selected Measurement Variable & $\begin{array}{c}\text { Variable } \\
\text { Abbreviation }\end{array}$ & $\begin{array}{c}\text { Description } \\
\text { and Score }\end{array}$ \\
\hline \multirow{6}{*}{$\begin{array}{l}\text { Negative work } \\
\text { situation }\end{array}$} & You can take a break when you wish & WS1 & \multirow{6}{*}{$\begin{array}{l}\text { 1.Always } \\
\sim 5 \text {.Never }\end{array}$} \\
\hline & You have enough time to get the job done & WS2 & \\
\hline & Your job gives you the feeling of work well done & WS3 & \\
\hline & You are able to apply your own ideas in your work & WS4 & \\
\hline & You have the feeling of doing useful work & WS5 & \\
\hline & You know what is expected of you at work & WS6 & \\
\hline \multirow{5}{*}{$\begin{array}{l}\text { Work-family } \\
\text { conflict }\end{array}$} & Worry about work when not working & F1 & \multirow{5}{*}{$\begin{array}{l}\text { 1.Never } \\
\sim 5 \text {.Always }\end{array}$} \\
\hline & Too tired after work to do household work & F2 & \\
\hline & Job prevents giving time to family & F3 & \\
\hline & Hard to concentrate on job because of family & $\mathrm{F} 4$ & \\
\hline & Family prevents giving time to job & F5 & \\
\hline \multirow{3}{*}{$\begin{array}{l}\text { Sleep-related } \\
\text { problems }\end{array}$} & Difficulty falling asleep & S1 & \multirow{3}{*}{$\begin{array}{l}\text { 1.Never } \\
\text { 5.Daily }\end{array}$} \\
\hline & Waking up repeatedly during the sleep & S2 & \\
\hline & Waking up with a feeling of exhaustion and fatigue & S3 & \\
\hline \multirow{6}{*}{$\begin{array}{c}\text { Job } \\
\text { dissatisfaction }\end{array}$} & At my work I feel full of energy & $\mathrm{J} 1$ & \multirow{4}{*}{$\begin{array}{l}\text { 1.Always } \\
\sim 5 \text {.Never }\end{array}$} \\
\hline & I am enthusiastic about my job & $\mathrm{J} 2$ & \\
\hline & Time flies when I am working & $\mathrm{J} 3$ & \\
\hline & In my opinion, I am good at my job & $\mathrm{J} 4$ & \\
\hline & I feel exhausted at the end of the working day & $\mathrm{J} 5$ & 1.Never \\
\hline & I doubt the importance of my work & J6 & $\sim 5$.Always \\
\hline
\end{tabular}

\subsection{Data Analysis and Structural Equation Model}

This study proposed hypotheses based on the literature review. The hypotheses are as follows:

- H1: Negative work situations positively affect sleep-related problems.

- H2: Work-family conflicts positively affect sleep-related problems.

- H3: Sleep-related problems positively affect job dissatisfaction.

This study merged two relationships to create a more robust model. Sleep-related problems were a dependent variable and an explanatory variable in the model. The relationship was verified by structural equation modeling (SEM). SEM has the advantage of estimating this kind of interdependence of several variables that reflect measurement errors.

Figure 1 shows the initial structural model. In Figure 1, ellipse means latent variable, and a rectangle is the measurement variable. $D i$ is a disturbance or residual, and $e i$ is measurement error.

In the structural equation model, negative work situation, which is a latent variable, is measured by 6 questionnaire items, work-family conflict by 5 questionnaire questions, sleep-related problems by 3 questionnaire questions, and job dissatisfaction by 6 questionnaire questions.

AMOS 18 and SPSS version 18.0 were used as analytical tools. The internal consistency of measured variables was performed by reliability analysis. Some measurement variables were eliminated by the standardized Cronbach's alpha. The convergent validity was confirmed through factor analysis. Path analysis was then performed to evaluate the proposed hypotheses. 


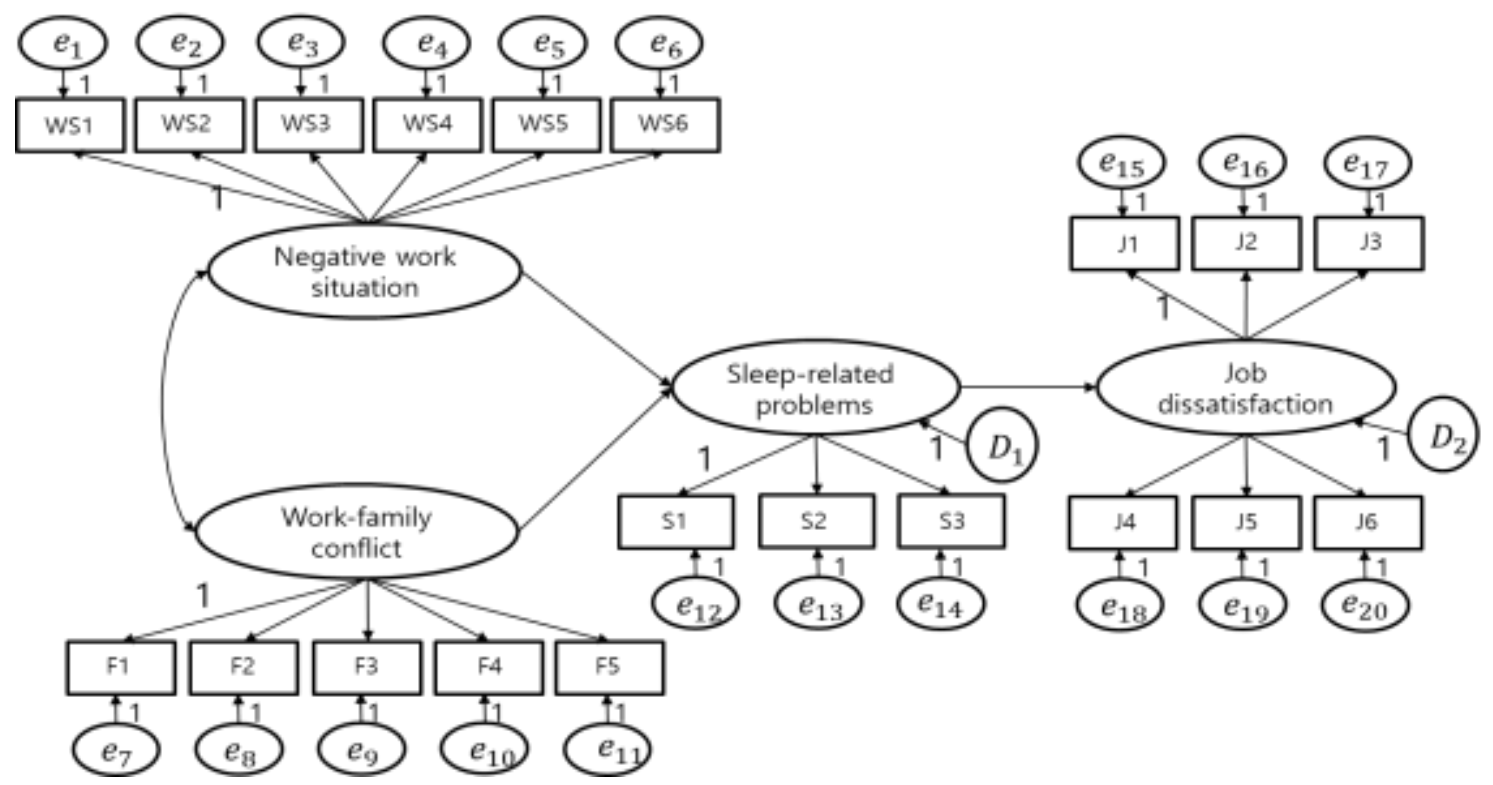

Figure 1. Conceptual model of this study. Rectangle represents measurement variable, and ellipse represents latent variable. $D i$ : disturbance or residual; $e i$ : measurement error.

\section{Results}

\subsection{Reliability Analysis}

Table 2 displays the final results of reliability analysis to ensure the internal consistency of the measurement variables. As shown in Table 2, two measurement variables in negative work situation and two measurement variables in job dissatisfaction were removed by Cronbach's alpha. The final result of reliability analysis yields a Cronbach's $\alpha$ value of 0.821 , and it is very satisfactory.

Table 2. Results of reliability analysis using Cronbach's Alpha.

\begin{tabular}{cccc}
\hline Latent Variable & $\begin{array}{c}\text { Initial Measurement } \\
\text { Variables }\end{array}$ & $\begin{array}{c}\text { Final Measurement } \\
\text { Variables }\end{array}$ & $\begin{array}{c}\text { Standardized } \\
\text { Cronbach's Alpha }\end{array}$ \\
\hline Negative work situation & 6 & 4 & 0.748 \\
Work-family conflict & 5 & 5 & 0.813 \\
Sleep-related problems & 3 & 3 & 0.821 \\
Job dissatisfaction & 6 & 4 & 0.800 \\
& Instrument Total & & 0.821 \\
\hline
\end{tabular}

\subsection{Exploratory Factor Analysis}

Factor analysis was useful for refining measures and evaluating construct validity.

In Bartlett's test and Kaiser-Meyer-Olkin (KMO) test results, Bartlett's test was significant ( $p<$ $0.001)$, and the KMO was above 0.60 (0.774). Factor analytical results, shown in Table 3, revealed that the factors could be classified into four dimensions: negative work situation, work-family conflict, sleep-related problems, and job dissatisfaction. From Tables 2 and 3, research variables and factors showed acceptable reliability and construct validity. 
Table 3. Results of exploratory factor analysis and construct validity.

\begin{tabular}{cccccc}
\hline \multirow{2}{*}{ Factor } & Measurement Variable & \multicolumn{4}{c}{ Component } \\
\cline { 3 - 6 } & & $\mathbf{1}$ & $\mathbf{2}$ & $\mathbf{3}$ & $\mathbf{4}$ \\
\hline \multirow{3}{*}{ Work-family conflict } & F3: Family & 0.811 & -0.006 & 0.185 & 0.043 \\
& F5: Responsibility & 0.774 & 0.220 & -0.038 & 0.035 \\
& F4: Concentration & 0.725 & 0.187 & -0.006 & 0.036 \\
& F2: Tired & 0.709 & 0.001 & 0.107 & 0.193 \\
& F1: Worry & 0.680 & 0.134 & -0.059 & 0.195 \\
\hline \multirow{3}{*}{ Job dissatisfaction } & J2: Enthusiastic & 0.234 & 0.772 & 0.085 & 0.126 \\
& J3: Time & 0.072 & 0.753 & 0.062 & 0.148 \\
& J4: Work well & 0.041 & 0.753 & 0.237 & 0.015 \\
& J1: Energy & 0.144 & 0.744 & 0.095 & 0.081 \\
\hline \multirow{3}{*}{ Negative work situation } & WS1: Break & -0.067 & -0.098 & 0.803 & 0.096 \\
& WS2: Enough time & 0.066 & 0.087 & 0.764 & 0.074 \\
& WS3: Feeling well & 0.107 & 0.323 & 0.715 & 0.105 \\
& WS4: Ideas & 0.070 & 0.324 & 0.632 & -0.040 \\
\hline \multirow{3}{*}{ Sleep related problems } & S1: Fall asleep & 0.101 & 0.100 & 0.082 & 0.874 \\
& S2: Waking up repeatedly & 0.106 & 0.158 & 0.016 & 0.867 \\
& S3: Exhaustion/fatigue & 0.196 & 0.068 & 0.119 & 0.760 \\
\hline & \% of Variance & 18.213 & 16.570 & 14.300 & 14.022 \\
& Cumulative (\%) & & 63.105 & \\
\hline \multirow{2}{*}{ Instrument Total } & Kaiser-Meyer-Olkin test & & 0.774 & \\
& Bartlett's test & & $p<0.001$ & \\
\hline & & & &
\end{tabular}

\subsection{Structural Model Assessment}

A chi-square test value usually determines the model fit, and other indices have been used for the assessment. The goodness of fit (GOF) was evaluated and compared with the suggested criteria shown in Table 4 . The goodness of fit indices in Table 4 represented an acceptable fit of the model $\left(\chi^{2}=\right.$ 202.898, $p<0.001 ; \mathrm{NFI}=0.821 ; \mathrm{CFI}=0.897 ; \mathrm{GFI}=0.878 ; \mathrm{TLI}=0.874 ; \mathrm{RMSEA}=0.076$ ).

Table 4. Results of model fit test.

\begin{tabular}{cccc}
\hline Goodness of Fit Index & Good Fit & Acceptable Fit & Structural Model \\
\hline$\chi^{2}$ & & & 202.898 \\
$\mathrm{df}$ & & & 98 \\
$\chi^{2} / \mathrm{df}$ & $<2$ & $2.0-5.0$ & 2.070 \\
$p$-value & $<0.001$ & 0.050 & $<0.001$ \\
NFI & $>0.90$ & $0.85-0.90$ & 0.821 \\
CFI & $>0.90$ & $0.85-0.90$ & 0.897 \\
GFI & $>0.90$ & $0.85-0.90$ & 0.878 \\
TLI & $>0.90$ & $0.85-0.90$ & 0.874 \\
RMSEA & $<0.06$ & $0.06-0.08$ & 0.076 \\
\hline
\end{tabular}

\subsection{Convergent Validity}

The convergent validity was confirmed by average variance extracted (AVE) and composite reliability (CR). In Table 5, CR values were between 0.784 and 0.874 (acceptable criteria: $>0.70$ ), so these results show strong composite reliability. The AVE values were also greater than correlations between variables, so the results supported convergent validity. 
Table 5. Convergent validity and correlations with variables.

\begin{tabular}{cccccc}
\hline Hypothesis & $\begin{array}{c}\text { Negative Work } \\
\text { Situation }\end{array}$ & $\begin{array}{c}\text { Work-Family } \\
\text { Conflict }\end{array}$ & $\begin{array}{c}\text { Sleep-Related } \\
\text { Problems }\end{array}$ & $\begin{array}{c}\text { Average Variance } \\
\text { Extracted (AVE) }\end{array}$ & $\begin{array}{c}\text { Composite } \\
\text { Reliability }\end{array}$ \\
\hline $\begin{array}{c}\text { Negative work } \\
\text { situation }\end{array}$ & & & & 0.478 & 0.784 \\
$\begin{array}{c}\text { Work-family } \\
\text { conflict }\end{array}$ & 0.217 & 0.323 & 0.468 & 0.814 \\
$\begin{array}{c}\text { Sleep-related } \\
\text { problems } \\
\text { Job }\end{array}$ & 0.250 & 0.403 & 0.312 & 0.687 & 0.866 \\
dissatisfaction & 0.479 & 0.636 & 0.874 \\
\hline
\end{tabular}

\subsection{Nomological Validity}

Figure 2 represents the direction of the correlation between latent variables. Figure 2 shows that the proposed relationships have the same directions, with relationships shown in Figure 2. The results supported the nomological validity.

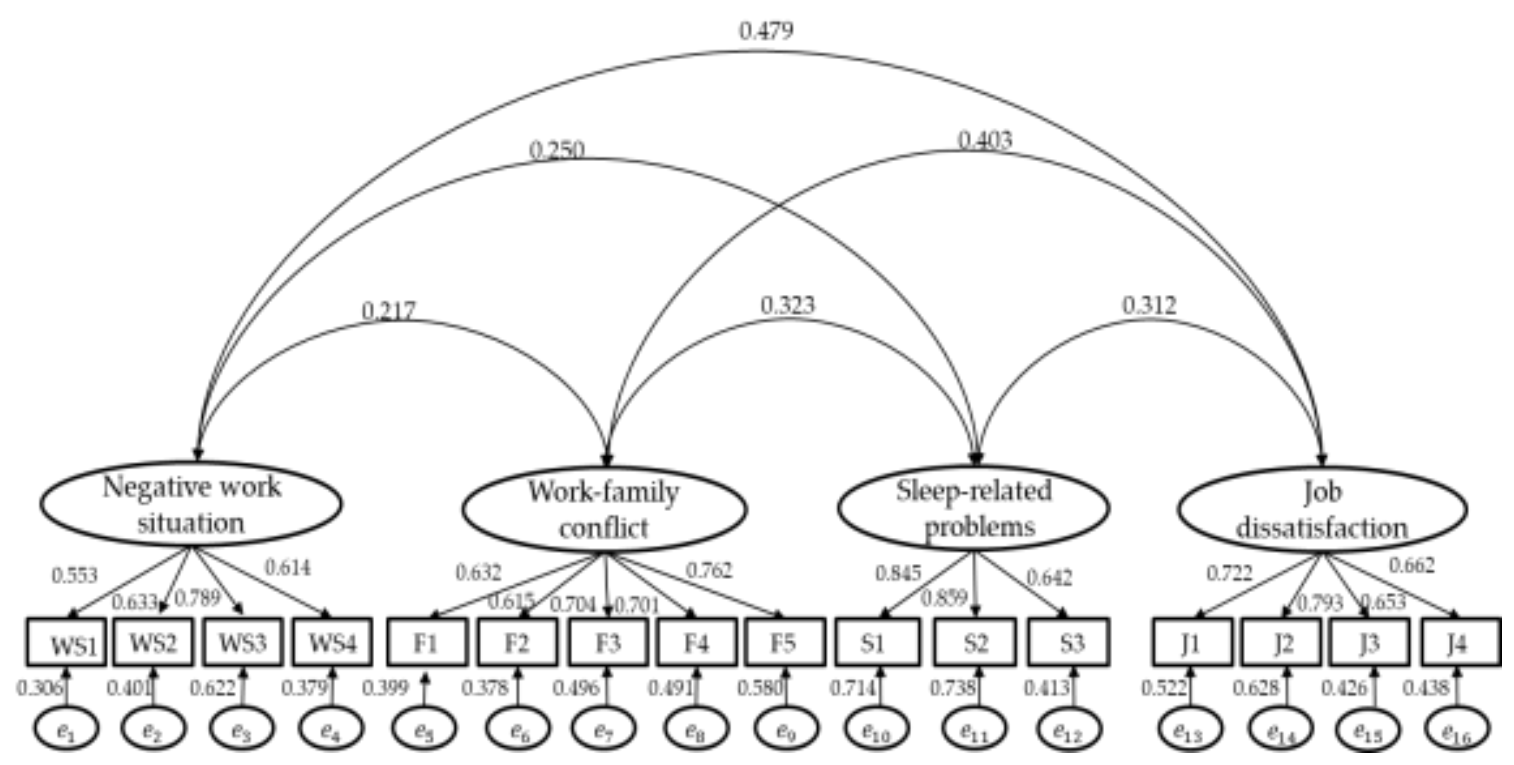

Figure 2. Result of confirmatory factor analysis. Rectangle represents measurement variable, and ellipse represents latent variable. $D i$ : disturbance or residual; $e i$ : measurement error.

\subsection{Hypothesis Testing of the Structural Model}

The structural model was evaluated to validate the hypothesized relationships. Table 6 represents the results of hypothesis testing for the proposed relationships among the constructs.

In Table 6, negative work situation and work-family conflict were found to have significantly positive effects on sleep-related problems. Thus, $\mathrm{H} 1$ and $\mathrm{H} 2$ were statistically validated. Similarly, sleep-related problems significantly influenced job satisfaction. H3, therefore, was statistically supported.

Table 6. Results of hypothesis testing for the proposed relationships.

\begin{tabular}{cccccc}
\hline Hypothesis & Paths & $\begin{array}{c}\text { Standardized } \\
\text { Coefficient }(r)\end{array}$ & $\begin{array}{c}\text { Critical } \\
\text { Ratio }\end{array}$ & $p$-Value & Result \\
\hline $\mathrm{H} 1$ & $\begin{array}{c}\text { Negative work situation } \\
\rightarrow \text { Sleep-related problems }\end{array}$ & 0.203 & 2.161 & 0.031 & Supported \\
$\mathrm{H} 2$ & $\begin{array}{l}\text { Work-family conflict } \\
\rightarrow \text { Sleep-related problems }\end{array}$ & 0.274 & 2.939 & 0.003 & Supported \\
$\mathrm{H} 3$ & $\begin{array}{c}\text { Sleep-related problems } \\
\rightarrow \text { Job dissatisfaction }\end{array}$ & 0.336 & 3.714 & $<0.001$ & Supported \\
\hline
\end{tabular}




\subsection{Effect of Work Situation and Work-Life Balance on Sleep-Related Problems and Job Satisfaction}

As shown in Figure 3, negative work situations positively affected sleep-related problems (standardized path coefficient $=0.203$ ). It can be interpreted that the higher the level of the negative work situation, the more significant influence on sleep-related problems. Among the measurement variables for a negative work situation, 'feeling well' (0.752) and 'enough time' (0.666) were found to be the influential variables.

The work-family conflict also had a significant impact on sleep-related problems (standardized path coefficient $=0.274$ ). In other words, a higher work-family conflict level led to a higher level of sleep-related problems. Among the measurement variables for work-family conflict, 'family' (0.825) and 'tired' (0.721) were found to be the influential variables.

Also, sleep-related problems were more affected by the level of work-family conflict $(0.274)$ than the negative work situation (0.203). Among the measurement variables for sleep-related problems, 'waking up repeatedly' (0.851) and 'difficulty fall asleep' (0.845) were the influential variables.

On the other hand, the sleep-related problems (standardized path coefficient $=0.336$ ) affected job dissatisfaction. That is, a higher level of sleep-related problems led to a higher level of job dissatisfaction. Among the measurement variables for job satisfaction, 'enthusiastic' (0.792) and 'energy' (0.731) were the influential variables.

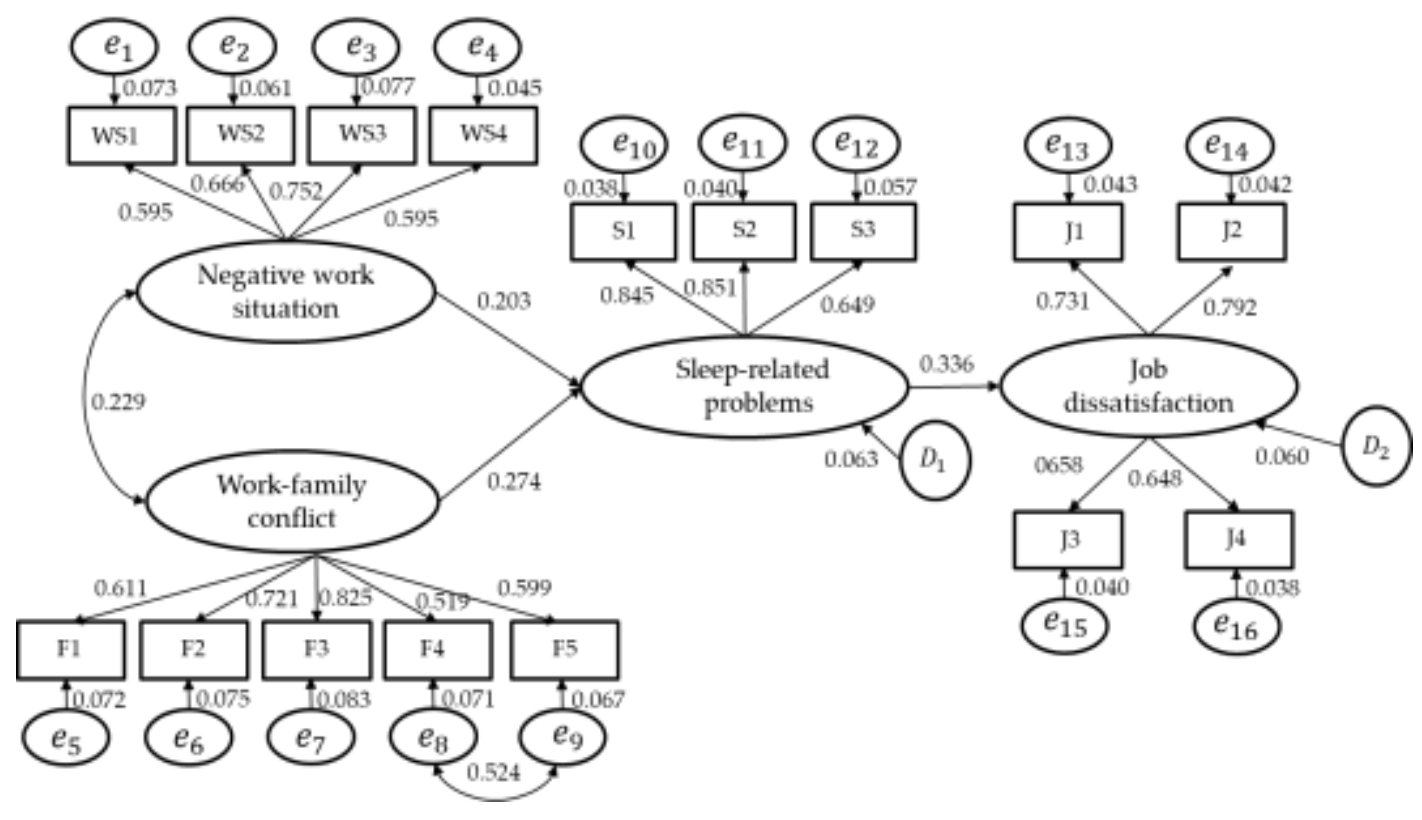

Figure 3. Final model of this study. Rectangle represents measurement variable, and ellipse represents latent variable. $D_{i}$ : disturbance or residual; $e_{i}$ : measurement error.

\section{Discussion}

Truck drivers are exposed to sleep-related problems and stress due to physical and mental fatigue [33]. Irregular shift schedules and extended driving hours are related to mental problems and adverse effects on health behaviors. Truck drivers are highly stressed by irregular working hours and shifts, leading to drowsy driving or dangerous driving situations. Truck drivers complain about not getting enough information and support for safety and health management. They work isolated from family and colleagues, so they often do not have access to health-related resources [34]. Furthermore, fatigue and sleep disturbances affect circadian rhythms and increase traffic crashes [25]. Therefore, driving schedule planning, work redesign, and health protection programs should be considered to prevent collisions [35].

Age-related declines in cognitive, perceptual, and motor capabilities negatively affect driving performance [36]. In South Korea, as the elderly population increases, the average age of truck 
drivers is rising. In this study, the proportion of respondents aged $\geq 60$ years accounted for $50.0 \%$ by reflecting the truck drivers' population ratio. Traffic crashes caused by elderly truck drivers are also increasing [1,5]. Thus, an active policy for elderly truck drivers is required. The driver-centered approach to the work environment and conditions can improve the work situation for safety and health $[37,38]$. Universal safety and design concepts can be an opportunity to enhance the working environment of older drivers and promote economic participation in society through policy and design considerations for seniors $[39,40]$.

Limiting driving time can reduce work-family conflict and drowsiness [41]. Measures to ensure the effectiveness of hours-of-service regulation and institutional aspects regarding working hours and break times can improve working conditions. For truck drivers, how to monitor and implement a safe driving strategy is essential. U.S. truck drivers are required to have electronic onboard monitoring to adhere to hours of service regulations [42].

Workplace health and wellness program is being recognized as potentially enhancing employee health, satisfaction, and productivity. Researchers recommend psychological counseling as a way to improve a driver's sleep-related problem. Workplace health promotion programs also emphasize changes in health behavior [43]. Comprehensive efforts on working condition improvements and workplace health programs are recommended to yield better driver health outcomes $[23,44]$ because comprehensive efforts could increase effectiveness and participation [37].

\section{Conclusions}

This research examined the interrelationships between negative work situation, work-family conflict, sleep-related problems, and job dissatisfaction. Based on the literature survey, this study tested three hypotheses on the interrelationships between negative work situation, work-family conflict, sleep-related issues, and job dissatisfaction. The results of this study suggested that negative work situation and work-family conflict significantly influence sleep-related problems in truck drivers. Also, truck drivers' sleep-related problems significantly affect their job dissatisfaction. The results of this study can be used to establish preventive policies for truck drivers' safety and health.

Author Contributions: Conceptualization, D.S.S. and B.Y.J.; methodology, D.S.S. and B.Y.J.; data collection \& analysis, D.S.S.; resources, D.S.S. and B.Y.J.; data curation, D.S.S.; writing-original draft preparation, D.S.S. and B.Y.J.; writing-review and editing, D.S.S. and B.Y.J.; supervision, D.S.S.; funding acquisition, D.S.S. All authors have read and agreed to the published version of the manuscript.

Funding: This research was funded by MOTIE (Ministry of Trade, Industry and Energy), grant number N0002430.

Acknowledgments: This research was financially supported by MOTIE (Ministry of Trade, Industry and Energy) and KITECH (Korea Institute of Industrial Technology) for Dong Seok Shin. Also, this research was financially supported by Hansung University for Byung Yong Jeong. The authors are grateful to the Occupational Safety and Health Research Institute (OSHRI) and the Korea Occupational Safety and Health Agency (KOSHA) for providing the raw data from the KWCS.

Conflicts of Interest: The authors declare no conflict of interest.

\section{References}

1. Lee, S.; Jeong, B.Y. Comparisons of traffic collisions between expressways and rural roads in truck drivers. Saf. Health Work 2016, 7, 38-42. [CrossRef] [PubMed]

2. Korean Standard Classification of Occupations. Available online: http://kssc.kostat.go.kr/ksscNew_web/ekss c/main/main.do\# (accessed on 9 September 2020).

3. Korean Standard Industrial Classification. Available online: http://kssc.kostat.go.kr/ksscNew_web/ekssc/ma in/main.do\# (accessed on 9 September 2020).

4. Transporation Survey: No. of Workers of Freight Trucking Industry. Available online: http://kosis.kr/eng/statisticsList/statisticsListIndex.do?menuId=M_01_01\&vwcd=MT_ETITLE\&parmTab Id=M_01_01\&statId=1978009\&themaId=\#SelectStatsBoxDiv (accessed on 9 September 2020).

5. Shin, D.S.; Park, M.H.; Jeong, B.Y. Human factors and severity of injury of delivery truck crashes registered for work-related injuries in South Korea. Ind. Eng. Manag. Syst. 2018, 17, 301-309. [CrossRef] 
6. Heavy and Tractor-Trailer Truck Drivers. Available online: https://www.bls.gov/ooh/transportation-and-mat erial-moving/heavy-and-tractor-trailer-truck-drivers.htm (accessed on 9 September 2020).

7. Smith, C.K.; Williams, J. Work related injuries in Washington State's trucking industry, by industry sector and occupation. Accid. Anal. Prev. 2014, 65, 63-71. [CrossRef] [PubMed]

8. Härmä, M. Workhours in relation to work stress, recovery and health. Scand. J. Work Environ. Health 2006, 32, 502-514. [CrossRef] [PubMed]

9. Hatami, A.; Vosoughi, S.; Hosseini, A.F.; Ebrahimi, H. Effect of co-driver on job content and depression of truck drivers. Saf. Health Work. 2019, 10, 75-79. [CrossRef]

10. Shen, X.; Yan, Y.; Li, X.; Xie, C.; Wang, L. Analysis on tank truck accidents involved in road hazardous materials transportation in China. Traffic Inj. Prev. 2014, 15, 762-768. [CrossRef]

11. Donmez, B.; Liu, Z. Associations of distraction involvement and age with driver injury severities. J. Saf. Res. 2015, 52, 23-28. [CrossRef]

12. Zhu, X.; Srinivasan, S. A comprehensive analysis of factors influencing the injury severity of large-truck crashes. Accid. Anal. Prev. 2011, 43, 49-57. [CrossRef]

13. Pylkkönen, M.; Sihvola, M.; Hyvärinen, H.K.; Puttonen, S.; Hublin, C.; Sallinen, M. Sleepiness, sleep, and use of sleepiness countermeasures in shift-working long-haul truck drivers. Accid. Anal. Prev. 2015, 80, 201-210. [CrossRef]

14. Santos, J.A.; Lu, J.L. Occupational safety conditions of bus drivers in Metro Manila, the Philippines. Int. J. Occup. Saf. Ergon. 2016, 22, 508-513. [CrossRef]

15. Apostolopoulos, Y.; Sönmez, S.; Shattell, M.M.; Belzer, M. Worksite-induced morbidities among truck drivers in the United States. J. Am. Assoc. Occup. Health Nurs. 2010, 58, 285-296.

16. Greenhaus, J.H.; Collins, K.M.; Shaw, J.D. The relation between work-family balance and quality of life. J. Voc. Behav. 2003, 63, 510-531. [CrossRef]

17. Grzywacz, J.G.; Carlson, D.S. Conceptualizing work-family balance: Implications for practice and research. Adv. Dev. Hum. Res. 2007, 9, 455-471. [CrossRef]

18. Striking a Balance: Reconciling Work and Life in the EU. Available online: https://www.eurofound.europa.eu/public ations/report/2018/striking-a-balance-reconciling-work-and-life-in-the-eu (accessed on 9 September 2020).

19. Zhang, T.; Chan, A.H.S. Sleepiness and the risk of road accidents for professional drivers: A systematic review and meta-analysis of retrospective studies. Saf. Sci. 2014, 70, 180-188. [CrossRef]

20. Apostolopoulos, Y.; Sönmez, S.; Shattell, M.M.; Gonzales, C.; Fehrenbacher, C. Health survey of US long-haul truck drivers: Work environment, physical health, and healthcare access. Work 2014, 46, 113-123. [CrossRef] [PubMed]

21. Lemke, M.K.; Apostolopoulos, Y.; Hege, A.; Sönmez, S.; Wideman, L. Understanding the role of sleep quality and sleep duration in commercial driving safety. Accid. Anal. Prev. 2016, 97, 79-86. [CrossRef] [PubMed]

22. Kanazawa, H.; Suzuki, M.; Onoda, T.; Yokozawa, N. Excess workload and sleep-related symptoms among commercial long-haul truck drivers. Sleep Biol. Rhythms 2006, 4, 121-128. [CrossRef]

23. Hege, A.; Perko, M.; Johnson, A.; Yu, C.H.; Sönmez, S.; Apostolopoulos, Y. Surveying the impact of work hours and schedules on commercial motorvehicle driver sleep. Saf. Health Work 2015, 6, 104-113. [CrossRef]

24. Pack, A.I.; Maislin, G.; Staley, B.; Pack, F.M.; Rogers, W.C.; George, C.F.P.; Dinges, D.F. Impaired performance in commercial drivers: Role of sleep apnea and short sleep duration. Am. J. Respir. Crit. Care Med. 2006, 174, 446-454. [CrossRef]

25. Philip, P.; Åkerstedt, T. Transport and industrial safety, how are they affected by sleepiness and sleep restriction? Sleep Med. Rev. 2006, 10, 347-356. [CrossRef]

26. Lambert, E.G.; Pasupuleti, S.; Cluse-Tolar, T.; Jennings, M.; Baker, D. The impact of work-family conflict on social work and human service worker job satisfaction and organizational commitment: An exploratory study. Adm. Soc. Work 2006, 30, 55-74.

27. Lambert, E.G.; Hogan, N.L.; Paoline, E.A.; Baker, D.N. The good life: The impact of job satisfaction and occupational stressors on correctional staff life satisfaction an exploratory study. J. Crime Justice 2012, 28, 1-26. [CrossRef]

28. Kahya, E. The effects of job characteristics and working conditions on job performance. Int. J. Ind. Ergon. 2007, 37, 515-523.

29. Harrison, D.A.; Newman, D.A.; Roth, P.L. How important are job attitudes? Meta-analytic comparisons of integrative behavioral outcomes and time sequences. Acad. Manag. J. 2006, 49, 305-325. [CrossRef]

30. 5th Korean Working Conditions Survey. Available online: http://oshri.kosha.or.kr/eoshri/resources/KWCSD ownload.do (accessed on 9 September 2020). 
31. 6th European Working Conditions Survey (2015) Questionnaire. Available online: https://www.eurofound.europa.e u/sites/default/files/page/field_ef_documents/6th_ewcs_2015_final_source_master_questionnaire.pdf (accessed on 9 September 2020).

32. Warr, P.; Cook, J.; Wall, T. Scales for the measurement of some work attitudes and aspects of psychological well-being. J. Occup. Psychol. 1979, 52, 129-148. [CrossRef]

33. Shattell, M.; Apostolopoulos, Y.; Sönmez, S.; Griffin, M. Occupational stressors and the mental health of truckers. Issues Ment. Health Nurs. 2010, 31, 561-568. [CrossRef]

34. Apostolopoulos, Y.; Lemke, M.; Sonmez, S. Risks endemic to long-haul trucking in North America: Strategies to protect and promote driver well-being. N. Solut. 2014, 24, 57-81. [CrossRef]

35. Dembe, A.E.; Erickson, J.B.; Delbos, R.G.; Banks, S.M. The impact of overtime and long work hours on occupational injuries and illnesses: New evidence from the United States. Occup. Environ. Med. 2005, 62, 588-597. [CrossRef]

36. Gentzler, M.D.; Smither, J.A. A literature review of major perceptual, cognitive, and/or physical test batteries for older drivers. Work 2012, 41, 5381-5383.

37. Pronk, N.P. Integrated worker health protection and promotion programs-Overview and perspectives on health and economic outcomes. J. Occup. Environ. Med. 2013, 55, S30-S37. [CrossRef]

38. Varianou-Mikellidou, C.; Boustras, G.; Dimopoulos, C.; Wybo, J.L.; Guldenmund, F.W.; Nicolaidou, O.; Anyfantis, I. Occupational health and safety management in the context of an ageing workforce. Saf. Sci. 2019, 116, 231-244. [CrossRef]

39. Kim, J.S.; Jeong, B.Y. Universal safety \& design; Transition from universal design to a new philosophy. Work 2020, 67. [CrossRef]

40. Baek, S.Y.; Jeong, B.Y. Universal safety \& design (USD) guideline in the era of an aged and sustainable society. J. Ergon. Soc. Korea 2020, 39, 303-312.

41. Jensen, A.; Dahl, S. Truck drivers hours-of-service regulations and occupational health. Work 2009, 32, 363-368. [CrossRef]

42. Kemp, E.; Kopp, S.W.; Kemp, E. Six days on the road-Will I make it home safely tonight? Examining attitudes toward commercial transportation regulation and safety. Int. J. Logist. Manag. 2013, 24, 210-229. [CrossRef]

43. Glanz, K.; Bishop, D.B. The role of behavioral science theory in development and implementation of public health interventions. Ann. Rev. Public Health. 2010, 31, 399-418. [CrossRef] [PubMed]

44. Baron, S.L.; Beard, S.; Davis, L.K.; Delp, L.; Forst, L.; Kidd-Taylor, A.; Liebman, A.K.; Linnan, L.; Punnett, L.; Welch, L.S. Promoting integrated approaches to reducing health inequities among low-income workers: Applying a social ecological framework. Am. J. Ind. Med. 2014, 57, 539-556. [CrossRef] 